\title{
XPS Analysis of the chemical degradation of PTB7 polymers for organic photovoltaics
}

\section{J. Kettle, ${ }^{* 1}$ Z. Ding, ${ }^{1}$ M. Horie, ${ }^{2}$ G.C. Smith ${ }^{3}$}

${ }^{1}$ School of Electronics, Bangor University, Dean St, Bangor, Gwynedd, LL57 1UT, Wales, UK *Contact details; Tel: +44 (0) 1248 382471; E-mail:j.kettle@bangor.ac.uk

${ }^{2}$ Department of Chemical Engineering, National Tsing Hua University, 101, Sec. 2, Kuang-Fu Road, Hsinchu, Hsinchu City 30013, Taiwan

${ }^{3}$ Department of Natural Sciences, University of Chester, Thornton Science Park, Chester CH2 4NU, UK

\section{Abstract}

The chemical degradation of the Poly[[4,8-bis[(2-ethylhexyl)oxy]benzo[1,2-b:4,5-b']dithiophene-2,6diyl][3-fluoro-2-[(2-ethylhexyl)carbonyl]thieno[3,4-b]thiophenediyl]] or ' PTB7' has been studied using X-ray Photoelectron Spectroscopy (XPS). This material system appears to be intrinsically unstable especially when illuminated in air and XPS studies confirm the rapid photo-degradation is related to changes in chemical structure of the polymer. In particular, XPS spectra show an initial reduction in relative $\mathrm{C}-\mathrm{C}$ intensity, suggests loss of the alkoxy side chains. This is followed by a dramatic increase in the level of oxygen-bonded species, especially C-O at $\sim 286.5 \mathrm{eV}$ and $\mathrm{C}(=0) \mathrm{O}$ at $289.2 \mathrm{eV}$, indicative of $\mathrm{COOH}$ and $\mathrm{OH}$ group formation, and oxidation of S. The XPS results support the view that using processing additives reduces the chemical stability of the polymer and provides insight into strategies to improve molecular design to ensure higher chemical stability.

\section{Graphical abstract}

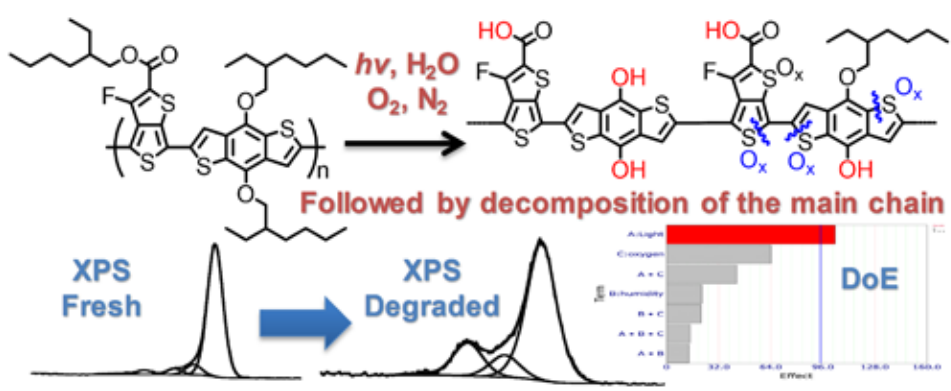




\section{Introduction}

Organic photovoltaics (OPVs) based on solution processable polymers and fullerenes have attracted remarkable interest for energy generation as they provide the potential for lower cost manufacture, using techniques such as roll-to-roll (R2R) printing. Recent research in this area has led to a reported power conversion efficiency (PCE) of over 11\% [1]. The behaviour of Organic Photovoltaic (OPVs) devices has been extensively researched over the past decade [2,3], particularly with respect to new donor co-polymers to optimise the performance. One such co-polymer is Poly[[4,8-bis[(2ethylhexyl)oxy]benzo[1,2-b:4,5-b']dithiophene-2,6-diyl][3-fluoro-2-[(2ethylhexyl)carbonyl]thieno[3,4-b]thiophenediyl]] or 'PTB7' which has reported efficiencies of up to $\sim 8 \%$. This donor-acceptor co-polymer consists of alternating benzodithiophene (BDT) and thienothiophene (TT) moieties as its backbone [4,5]. Despite the significant research progress in understanding the experimental application and fundamental physics of this material system, there are only a few reports of the long term stability of this material system.

Most studies have focused on degradation in devices and showed PTB7 is a relatively unstable material $[6,7,8]$, although the stability could be enhanced by higher molecular weights and inverted architectures. The use of processing additives has been shown to reduce stability and this has been explained as due to increased photo-bleaching [9]. Razell-Hollis et al. studied the photodegradation using Raman spectroscopy study on blended PTB7:PC 71 BM films and showed that the degradation pathway initially occurs due to oxidation of the BDT groups, which alters the electron density of the neighbouring TT unit and induces conjugation-breaking cycloaddition of $\mathrm{O}_{2}[10]$. The effect of degradation on carrier concentrations in the active layer has been studied using Capacitance-voltage (C-V) measurements and showed rapid increases in the series resistance in ageing experiments, due to contact effects, possibly causing the creation of an isolation layer between the polymer layer and the metallic contact [11].

X-ray photoelectron spectroscopy (XPS) has often been used for characterising chemical changes in active layer material with time. Recently, Kettle et al applied this for studying the photo degradation of PCPDTBT [12]. The work provided insight into degradation pathways when light soaked. Most XPS work has focused on studying the degradation of P3HT using XPS, for example, Hintz et al. looked at exposing P3HT for short periods to oxygen under dark and illumination and showed that both physisorbed and photo-oxidised oxygen is present [13]. Seo et al. studied longer term degradation detail and showed the formation of sulfoxide (R-SO-R) on the sulphur atom of the thiophene ring [14]. Changes in the oxidised C 1s spectra were mostly attributed to degradation of the side chain, in particular $\mathrm{C}-\mathrm{OH}$ (alpha-unsaturated alcohol). Krebs et al. also studied long-term degradation in $\mathrm{P} 3 \mathrm{HT}: \mathrm{PC}_{61} \mathrm{BM}$ samples using light soaking [15] and showed XPS spectra with broad $\mathrm{sp}^{2}$ 
peaks, which was interpreted as due to chain scission between the thiophene units in the polymer backbone, or the loss of side-chains. At longer exposure times, it was shown that the aromatic structure was broken and R'-SO $\mathrm{S}_{x}$ groups formed. Recently, Darlatt et al studied the stability of PTB7 inside a UHV system with external radiation sources and showed that UV irradiation in vacuum still induces chemical changes [16].

In this paper, we present XPS studies of the degradation of the PTB7 polymer under different environmental conditions. Initially, the results of XPS studies of samples illuminated in the presence of air to provide an insight into the mechanisms by which the polymer degrades. Finally, the susceptibility of PTB7 degradation in different environmental conditions is then studied.

\section{Experimental}

\subsection{Materials preparation}

Samples were prepared on glass substrates which were cleaned prior to coating. All PTB7 was synthesised in house as reported elsewhere [6] and the chemical structure is shown in figure 1. To study the changes in PTB7-devices with time, three samples sets were prepared. The first sample consisted of neat PTB7 film, to allow the polymer degradation to be studied in isolation. PTB7 is normally blended with an acceptor material such as a fullerene derivative in OPV active layers. Therefore, two samples were prepared consisting of pristine $[6,6]$-Phenyl- $\mathrm{C}_{71}$-butyric acid methyl ester $\left(P C_{71} B M\right)$, purchased from Nano-C Inc. Finally, three layers were also prepared in which the polymer was mixed with the fullerene derivative and the processing additive 1,8-Diiodooctane (DIO) to replicate the active layer composition in a device. DIO or similar alkanethiols are used in almost all reports of high efficiency OPVs and acts as a second non-reacting solvent $[17,18]$. It has been shown that the incorporation of a few volume percent of DIO into the blend improves the Power Conversion Efficiency (PCE) by about a factor of two. PTB7 and PC $\mathrm{C}_{71} \mathrm{BM}$ were blended with weight ratios $1: 1.5$, respectively, and were mixed with chlorobenzene solvent using a concentration of $30 \mathrm{mg} / \mathrm{mL}$. For layers with additives, DIO was added with a concentration of $24 \mathrm{mg} / \mathrm{mL}$. Prior to coating, all blends were allowed to dissolve for 24 hours on a hot plate stirrer and filtered using a $0.45 \mu \mathrm{m}$ PTFE filter.

All coatings were undertaken in a glovebox and annealed at $80^{\circ} \mathrm{C}$ for 30 minutes to remove any residual solvent; a procedure optimised for device fabrication [6]. After initial XPS analysis the samples were aged by light soaking non-encapsulated films for 300 hours using a Class A solar simulator, which was calibrated at 1 Sun of irradiance. The ageing was conducted in an air- 
conditioned room with relative humidity of $35 \pm 5 \%$ and ambient temperature of $20 \pm 5^{\circ} \mathrm{C}$.

Subsequently, the samples were re-measured using XPS to evaluate changes in the chemical structure at intervals of 25,100 and 200 hours of testing.

For section 3.3, screening of the factors that affect PTB7 degradation was conducted using a two-level, full factorial design of experiment solution. Three different environmental stress conditions were studied (light, humidity and atmosphere) to see the relative effect of each condition upon the stability of the PTB7 polymer. Two levels of stress were applied (i.e. light - 1 sun \& 0 sun, relative humidity- $5 \% \& 60 \%$, atmosphere $-\mathrm{N}_{2}$ and compressed air). For analysis, ReliaSoft's DOE++ software was used.

\subsection{XPS experiments}

The XPS data were acquired using a bespoke ultra-high vacuum system fitted with a Specs GmbH Focus 500 monochromated Al Ka X-ray source, Specs GmbH Phoibos 150 mm mean radius hemispherical analyser with 9-channeltron detection, and a Specs GmbH FG20 charge neutralising electron gun. Survey spectra were acquired over the binding energy range $1100-0 \mathrm{eV}$ using a pass energy of $50 \mathrm{eV}$ and high resolution scans were made over the $\mathrm{C} 1 \mathrm{~s}, \mathrm{O} 1 \mathrm{~s}, \mathrm{~S} 2 \mathrm{p}$ and $\mathrm{F} 1 \mathrm{~s}$ lines using a pass energy of $15 \mathrm{eV}$. In each case, the analysis was an area-average over a region approximately 2 $\mathrm{mm}$ in diameter on the sample surface. The monochromator X-ray source was operated at a reduced power of $12 \mathrm{kV} 15 \mathrm{~mA}$ (180W) compared to the manufacturer's recommended maximum of $15 \mathrm{kV} 26.6 \mathrm{~mA}(400 \mathrm{~W})$ to reduce the possibility of X-ray induced degradation during analysis. Note also that in this design of system, the X-ray source is remote from the sample by approximately $1 \mathrm{~m}$ and so there are no thermal- or Bremsstrahlung-induced degradation effects. Charge compensation was by a low energy ( $5 \mathrm{eV}$ ) electron flood, and spectra were charge corrected to the hydrocarbon C$\mathrm{C}$ component of the $\mathrm{C} 1 \mathrm{~s}$ peak at $285.0 \mathrm{eV}$. The energy scale of the instrument is calibrated according to ISO standard 15472, and the intensity scale is calibrated using an in-house method traceable to the UK National Physical Laboratory. The information depth in XPS analysis is normally taken as three times the effective electron attenuation length, typically $3-3.5 \mathrm{~nm}$ for the $\mathrm{C} 1 \mathrm{~s}$ line in organic materials, and was therefore approximately $10 \mathrm{~nm}$ in the measurements reported here. Quantification data used in this paper were obtained from the high resolution data.

\section{Results}

\subsection{Light soaking of PTB7 in ambient conditions}

Table 1 shows the stoichiometry of PTB7 at 0 hours and after ageing for 24 and 200 hours as determined from the XPS analysis. The approximate stoichiometry from the molecular structure 
$\left(\mathrm{C}_{40} \mathrm{O}_{4} \mathrm{~S}_{4} \mathrm{~F}\right)$ should be $82.0 \% \mathrm{C}, 8.0 \% \mathrm{O}, 8.0 \% \mathrm{~S}$ and $2 \% \mathrm{~F}$ by atom $\%$ composition, excluding $\mathrm{H}$, which is not detected by XPS. Therefore, the fresh sample shows a very good agreement with the expected stoichiometry, with slightly lower $\mathrm{O}$ and slightly higher $\mathrm{S}$ than expected from the molecular structure. These small differences may be due to the orientation of the molecule on the surface, e.g. if the $\mathrm{S}$ groups are more oriented towards the outer surface then the apparent $\mathrm{S}$ concentration would be raised.

Upon ageing, the PTB7 showed significant increases in O (oxidation) after 24 and 200 hours. An increases in $\mathrm{N}$ was also observed and trace amounts of $\mathrm{Na}, \mathrm{Sn}$ and $\mathrm{Si}$ were detected, due to a combination of surface contaminants and pinhole formation. There were small losses in the amounts of $\mathrm{F}$ and $\mathrm{S}$, but this could be due to the uptake of oxygen and renormalisation of the composition to 100 atom $\%$ (see below).

To understand the changes better, high-resolution scans were made over the individual photoelectron lines and curve-fitted to known reference data for polymers [19]. Figure 2 shows the results of curve-fitting the $C 1 s, 01 s$ and S $2 p$ data for the fresh, 24 hour aged and 200 hour aged PTB7.

The data for the fresh sample shown in Figure 2(a), 2(d) and 2(g) are in good agreement with the expected chemical structure for PTB7. The C 1s peak shows a symmetric hydrocarbon-like main component at $285.0 \mathrm{eV}$ due $\mathrm{C}-\mathrm{C}$ bonding in the side chains and aromatic rings. The weaker component at approximately $287 \mathrm{eV}$ is due to the presence of the $\mathrm{C}-\mathrm{O}$ and $\mathrm{C}-\mathrm{S}$ bonds in the molecule, not separately resolvable. The component at approximately $289 \mathrm{eV}$ is due to contributions from $\mathrm{C}(=\mathrm{O}) \mathrm{O}$ and $\mathrm{C}-\mathrm{F}$ bonds, also not separately resolvable. A very weak component at approximately $291.3 \mathrm{eV}$ is attributed to shake-up on photoemission from the unsaturated bonds in the aromatic ring structures. The $\mathrm{O} 1 \mathrm{~s}$ spectrum shows a major component at approximately 532.9 $\mathrm{eV}$ due to $\mathrm{C}-\mathrm{O}-\mathrm{C}$ bonds and a lower intensity component at approximately $531.8 \mathrm{eV}$ due to oxygen in $\mathrm{C}=\mathrm{O}$ bonds. The weaker component at higher binding energy is an X-ray excited Na KLL Auger peak arising from a low level of contamination, below the detection limit for the Na 1s peak.

The $S 2 p$ spectrum shows the $S 2 p_{3 / 2}-2 p_{1 / 2}$ doublet with the $2 p_{3 / 2}$ component at $164.2 \mathrm{eV}$ typical of sulphur in C-S bonds as expected from the PTB7 molecular structure. In the peak fitting, doublet separations and area ratios were constrained to $1.25 \pm 0.05 \mathrm{eV}$ and 2:1 respectively. A very low level of oxidation was detected, as seen from the very weak contribution to intensity at approximately $168 \mathrm{eV}$, and is due to exposure to the laboratory atmosphere between manufacture and analysis. 
After 24 hours of ageing under AM1.5G in artificial sunlight, significant changes in the XPS data were already visible as seen in Figures $2(b),(d)$ and (e). The $C 1$ s peak showed a dramatic increase in the level of oxygen-bonded species, especially C-O at $\sim 286.5 \mathrm{eV}$ and C(=O)O at $289.2 \mathrm{eV}$. The relative reduction in $\mathrm{C}-\mathrm{C}$ intensity suggests loss of the alkoxy side chains. The $\mathrm{O} 1 \mathrm{~s}$ spectrum showed a strong increase in the component at $\sim 532 \mathrm{eV}$, attributable to oxygen in $\mathrm{C}=\mathrm{O}$ bonds but also to sulphur-bonded oxygen in sulphone groups, $-\mathrm{SO}_{3}{ }^{-}$in agreement with the presence of a significant contribution to the $S 2 p$ intensity from oxidised S at $~ 168 \mathrm{eV}$. The trends seen after 24 hours exposure to AM1.5G artificial sunlight continued after 200 hours, as shown in Figure 2 (c), (f) and (i). The proportion of oxygen-bonded components in the $\mathrm{C} 1 \mathrm{~s}$ spectrum increased, along with the proportion of oxidised sulphur in the $S 2 p$ spectrum. The relative ratio of the two components in the 0 1s peak did change significantly, however, the increase in oxidised sulphur indicates that the proportion of $\mathrm{C}=\mathrm{O}$ bonding in the $\mathrm{C}=\mathrm{O} / \mathrm{S}-\mathrm{O}$ component of the $\mathrm{O} 1 \mathrm{~s}$ at $\sim 532 \mathrm{eV}$ is expected to have decreased. Note that after ageing the $01 \mathrm{~s} \mathrm{signal} \mathrm{is} \mathrm{more} \mathrm{intense} \mathrm{and} \mathrm{tends} \mathrm{to} \mathrm{mask} \mathrm{the} \mathrm{visibility} \mathrm{of}$ the Na KLL component in this spectral region

Data for the F 1s peak were also acquired (not shown). These showed a single component in the fresh sample at $687.6 \mathrm{eV}$ due to $\mathrm{C}-\mathrm{F}$ bonds. With exposure to artificial sunlight, the peak weakened in intensity but there was no significant change in lineshape or binding energy. F was lost during sunlight exposure, but the $F$ remaining was not in a changed chemical state. This could be due to the relative strength of the $\mathrm{C}-\mathrm{F}$ bond $\left(441.0 \mathrm{~kJ} \mathrm{~mol}^{-1}\right)$ which is substantially greater than C-S (259.4 $\left.\mathrm{kJ} \mathrm{mol}^{-1}\right)$ or $\mathrm{C}-\mathrm{C}\left(347.7 \mathrm{~kJ} \mathrm{~mol}^{-1}\right)$, making it less susceptible to degradation during photoirradiation.

$\mathrm{N}$ 1s peaks were detected after aging for 24 and 200 hours. In both cases, the $N$ 1s signal showed a main component at $\sim 402 \mathrm{eV}$ and a weaker component at $\sim 400-401 \mathrm{eV}$. The binding energy of the weaker component indicates an electronically neutral environment such as an organic (e.g. amine bonding) and the $402 \mathrm{eV}$ component is indicative of a protonated form. These are typical of $\mathrm{N}$ absorbed onto a range of surfaces from the atmosphere and are therefore likely to have arisen from this source and are not thought relevant to the photo-induced degradation of PTB7.

\subsection{Light soaking of PTB7:PC ${ }_{71} B M$ films in ambient conditions}

Degradation of PTB7 polymer in blends with $\mathrm{PC}_{71} \mathrm{BM}$ have also been studied and the effect of using process additive considered. The process conditions are discussed in section 2. Table 2 shows the measured chemical stoichiometry of PTB7:PC ${ }_{71} \mathrm{BM}$ with and without $\mathrm{DIO}$ (the processing additive) at 0 and 200 hours. 
The fresh PTB7:PC ${ }_{71} B M$ sample showed slightly more $C$ and less $\mathrm{O}, \mathrm{S}$ and $\mathrm{F}$ than measured from pure PTB7, due to the presence of $\mathrm{PC}_{71} \mathrm{BM}$. From the expected atom $\%$ compositions of the pure components, the data suggest the surface region analysed to be $\sim 30 \% \mathrm{PC}_{71} \mathrm{BM}$ and $\sim 70 \% \mathrm{PTB} 7$, showing PTB7 enrichment of the surface after the coating process. The small amount of Si detected was probably from the underlying glass substrate, suggesting possible occasional pinholes in the film.

Light soaking of the PTB7: PC $_{71} \mathrm{BM}$ sample (without DIO) for $200 \mathrm{hr}$ caused a substantial increase in $\mathrm{O}$ and lowering of the level of $\mathrm{C}$, near-disappearance of $\mathrm{F}$ peak, a slight loss of $\mathrm{S}$, the appearance of $\mathrm{N}$ and a small amount of $\mathrm{Na}$, and an increase in the amount of $\mathrm{Si}$. The increase in $\mathrm{O}$ indicates oxidation in both polymer and fullerene, as evidenced in the $C 1 s$ and $S 2 p$ peaks (see figure 3). As for the PTB7 samples, the data indicate reaction with atmospheric $\mathrm{N}$ during light exposure. Loss of $\mathrm{F}$ occurred during exposure, with no apparent change in the chemical bonding of the residual $\mathrm{F}$, as was the case for PTB7. The increase in Si may indicate some structural change to the film during light exposure, possibly resulting in increased exposure of the substrate.

The fresh sample with DIO showed very similar composition to the sample prepared without DIO, but with a slightly raised level of S. Previous studies on PCPDTBT have shown significant differences in XPS data between samples that include additives and those do not [12], so this is quite surprising, but is likely to be material dependent. After light exposure, the sample with ODT also showed similar trends to that without. The primary difference was seen in the $S 2 p$ peak. Samples with DIO showed S is $88 \%$ of present in an oxidised state, rather than the $79 \%$ seen for the sample without ODT. This supports the view of Kopidakis et al who showed that DIO increases the photodegradation of the polymer [9]. Previous XPS work has used the C:S ratio to investigate the morphological changes in the active layer $[12,20,21]$, although admittedly at the surface rather than the bulk. The C:S ratio can be used to infer the proportion of polymer at the top surface. For samples made without DIO, the C:S ratio reduces by $31 \%$ after light soaking, whereas with DIO, the ratio decreases by the lesser amount of $21 \%$. Therefore, the XPS data indicates that the difference in device degradation is likely to be due to greater chemical instability with DIO and less due to morphological changes.

To study some of the changes, individual curve fitting of the $C 1 s, 01 s$, and $S 2 p$ lines was undertaken, as shown in Figure 3. As the differences for material with and without DIO were minimal, only PTB7:PC ${ }_{71} B M$ with DIO is shown. The data for the fresh PTB7:PC $C_{71} B M$ with DIO are shown in Figure $3(a),(c)$ and (e) respectively. The $O 1$ s and S $2 p$ peaks were very similar to those seen for the fresh PTB7 sample (Figure 2 (d) and (g) respectively). The C 1s spectrum showed a 
narrower main peak with slightly more pronounced $\mathrm{C}-\mathrm{O} / \mathrm{C}-\mathrm{S}, \mathrm{C}=\mathrm{O}$ and $\mathrm{C}(=\mathrm{O}) \mathrm{O}-/ \mathrm{C}-\mathrm{F}$ components at increasing binding energy. The improved resolution, resulting in the separation of the $C=0$ component, is due to the improved conductivity of the material as a result of inclusion of $\mathrm{PC}_{71} \mathrm{BM}$ in the blend. The weak plasmon loss or shake-up feature at approximately $291 \mathrm{eV}$ is slightly stronger than was seen for the pure PTB7 material, also as a consequence of inclusion of the fullerene material of the $\mathrm{PC}_{71} \mathrm{BM}$.

After ageing, the $\mathrm{C}$ 1s peak broadened out, indicating a range of very similar un-resolved states. There is a substantial increase in the relative intensities of the oxygen-bonded components at $\sim 287.4$ (indicating formation of carbonyl groups) and $289 \mathrm{eV}$ (indicating a substantial increase in the proportion of ester or acid/acetate groups present). These two components make up $29 \%$ of the total carbon intensity.

As was the case for the pure PTB7 sample, the 01 s peak after ageing was more intense, and showed a higher proportion of the lower binding energy component, attributed to oxygen in either $\mathrm{C}=\mathrm{O}$ or sulphur-bonded groups. The presence of sulphur-bonded oxygen is confirmed by the high proportion of oxidised S seen in the S $2 p$ spectrum after ageing, as shown in Figure 3(f). This indicates that mixing the PTB7 and PC71BM components in the OPV polymer blend has no effect on the ageing behaviour of the $\mathrm{S}$. In polymers such as $\mathrm{P} 3 \mathrm{HT}$, it has been deduced that by blending the polymer with PCBM, the chemical stability of the polymer is enhanced. This appears not the case with PTB7.

$\mathrm{F}$ 1s peaks were measured and a single peak at $\sim 687.6 \mathrm{eV}$ binding energy was seen at 0 hours (not shown). This is fully consistent with C-F bonding, again as expected from the known PTB7 structure. Only a very weak peak was detected at 200 hours, indicating approximately 0.1 atom \% F remaining.

\subsection{Exposing PTB7 to different environments}

After considering the degradation of PTB7 polymer and blends during light soaking, further experiments were conducted in which the samples were degraded in a controlled atmosphere to investigate the relative influence of oxygen, humidity and light. Table 3 summarises the experimental data and shows the expected stoichiometry and changes in stoichiometry with different combinations of light, humidity and oxygen exposure.

The composition of the PTB7 unused fresh reference is included in the table for reference, in agreement with the expected stoichiometry from the molecular structure. As for the artificial 
sunlight aged samples, high resolution spectra were acquired over the $C 1 s, 0$ s and $S 2 p$ lines. Here, the data are not shown; instead the proportion of carbon and sulphur found in oxygen-bonded states are included in the Table. Overall, the data show a trend of increasing oxygen content correlating with increasing severity of treatment. This trend of increasing oxygen content was found to correlate reasonably well with increasing oxygen-bonded components in the $S 2 p$ peak, indicating oxidation of the sulphur groups.

The $\mathrm{C}$ in an O-bonded state provides useful insight into the degradation of PTB7. The reference has around $10 \%$ of the $\mathrm{C}$ in $\mathrm{O}$-bonded states, which is correct from the expected molecular structure. However, the exposed samples appear to reduce from this value, and then exceeding the expected value only at the most severe treatments of 3 hours of light in air. This effect can be explained by the presence of alkoxy substituents in the BDT and TT groups in PTB7. The data suggests the polymer experiences loss of alkoxy side chains, with simultaneous oxidation of the $S$ in the aromatic groups as a first step degradation pathway. A second step degradation is observed with increasing $\mathrm{C}-\mathrm{O}$ and $\mathrm{C}=\mathrm{O}$ bonds, related to oxidation of the $\mathrm{C}$ in the remaining side chains and aromatic group. The fluorine level and state stayed relatively unchanged through the series of samples, in contrast with the results reported in section 3.1 and 3.2 above where, although the chemical state of $F$ was not affected the overall level of $F$ was reduced as a consequence of artificial sunlight exposure.

To summarise the findings, Figure 4 shows anticipated chemical changes experienced by PTB7 when light soaked. The high level of oxygen observed in tables 1-3 ( 30\%) indicates almost certainly that the pi conjugation of the polymer will be disrupted. Ordinarily, this would be noted by the changes in the C-C spectra, whereby the hydrocarbon -like and graphite-like $\mathrm{C}-\mathrm{C}$ bonds are normally distinguishable from one another [12]. However, it was not possible to distinguish these apart with the PTB7 material system. Nevertheless, previous reports of donor acceptor copolymers indicate that the main chain decomposes upon ageing $[12,14]$. This will almost certainly have an impact upon the photophysical properties and conductivity of the polymer. This view is supported by a number of other papers, which have studied the degradation of the PTB7 material system, whereby a strong change in colour and solar cell performance has been noted $[8,9,11,12$,$] . This$ severe oxidation has been noted using surface analysis technique, so whilst high levels of oxygen have been observed at the surface, consistent with previous literature [12,21], it is quite plausible that the oxidation levels are lower within the bulk of the material.

To quantitatively identify how the variations in light, humidity and atmosphere affect the stability of PTB7, Design of Experiments has been used to investigate the output response 
(degradation) as a function of input variable (environmental conditions). As oxidised carbon experiences a decline, followed by an increase, only oxidised sulphur has been considered as an 'output response' for this analysis. The significant effects and interactions have been ranked relative to one another using a two-level factorial design and plotted as a Pareto chart in Figure 5.

Discussions of the stress levels and software analysis is set out in section 2.1. To understand which factors significantly affect the degradation, and whether the interaction between two factors significant, $T$ values for each single factor and interaction were calculated. A significance level of $10 \%$ was used for this analysis, and, if the T value was less than this critical value, this factor was considered to have a significant effect upon the degradation and is displayed in red in figure 5, over the range of the environmental conditions that were applied.

The data in Figure 5 shows that the polymer PTB7 is significantly unstable under illumination, and this is the only significant effect. As discussed, this instability is likely to be due to the presence of the alkoxy side chains in polymers, which is known to have a negative impact on the polymer stability due to cleavage of the $\mathrm{C}-\mathrm{O}$ bond, which occurs even in the absence of $\mathrm{O}_{2}$. The $\mathrm{C}-\mathrm{O}$ bonds in the alkoxy side chain are likely to form $\mathrm{R}-\mathrm{COOH}$, which will disrupt $\pi$ conjugation and subsequent charge transfer/light absorption. The various oxidation of $\mathrm{C}-\mathrm{C}$ and $\mathrm{C}=\mathrm{C}$ in the polymer backbone will also disrupt the conjugation. This in part explains the data of Kopidakis et al [9], who saw obvious changes in optical appearance of the photopolymer with ageing. Afterwards, there are various oxidation routes of $C$ that occur in PTB-7; oxidation of $C$ in the polymer backbone, disrupting its conjugation arrangement. The photoactive material also appears to be vulnerable to oxygen, and oxygen under illumination is also shown to have an effect. Overall, the oxidation of sulphur due to humidity does not appear to be as significant as light and oxygen exposure, over the range stresses tested. This is quite possibly because of the hydrophobic property of such polymers.

\section{Conclusions}

In summary, the evaluation of chemical degradation of PTB7 films has been studies using XPS analysis. Using the technique spectral changes have been identified that indicate changes in the chemical structure. After ageing, PTB7 shows significant elevation in oxygen-content as well as break-up of aromatic rings, loss of side chains and formation of $\mathrm{R}^{\prime}-\mathrm{SO}_{x}$ groups. Degradation of the polymer under controlled atmospheres supports the view that degradation of PTB7 is a 2-step process and is particularly susceptible to illumination in the presence of oxygen. The instability of this polymer to light and oxygen is likely to be due to the presence of the alkoxy side chains, which cleaves of the $\mathrm{C}-\mathrm{O}$ bond even in low $\mathrm{O}_{2}$ environments. The $\mathrm{C}-\mathrm{O}$ bonds in the alkoxy side chain are 
likely to form $\mathrm{R}-\mathrm{COOH}$, which will disrupt $\pi$ conjugation and subsequent charge transfer/light absorption and leads to the rapid degradation of devices made with this material system. It is clear that removal of these groups in this material system and others could aid the long term stability of OPV devices. The XPS results support previous studies that show the use of a processing additives has an impact on the chemical stability of the polymer.

\section{$\underline{\text { References }}$}

[1] Green, M.A., Emery, K., Hishikawa, Y., Warta, W. and Dunlop, E.D., 2015. Solar cell efficiency tables (Version 45). Progress in photovoltaics: research and applications, 23(1), pp.1-9.

[2] Lu, L., Kelly, M.A., You, W. and Yu, L., 2015. Status and prospects for ternary organic photovoltaics. Nature Photonics, 9(8), pp.491-500.

[3] Gevorgyan, S.A., Madsen, M.V., Roth, B., Corazza, M., Hösel, M., Søndergaard, R.R., Jørgensen, M. and Krebs, F.C., 2016. Lifetime of organic photovoltaics: status and predictions. Advanced Energy Materials, 6(2).

[4] Lu, L. and Yu, L., 2014. Understanding low bandgap polymer PTB7 and optimizing polymer solar cells based on it. Advanced Materials, 26(26), pp.4413-4430. [5] PTB7 report

[6] Ding, Z., Kettle, J., Horie, M., Chang, S.W., Smith, G.C., Shames, A.I. and Katz, E.A., 2016. Efficient solar cells are more stable: the impact of polymer molecular weight on performance of organic photovoltaics. Journal of Materials Chemistry A, 4(19), pp.7274-7280.

[7] Kim, W., Kim, J.K., Kim, E., Ahn, T.K., Wang, D.H. and Park, J.H., 2015. Conflicted Effects of a Solvent Additive on PTB7: PC71BM Bulk Heterojunction Solar Cells. The Journal of Physical Chemistry C, 119(11), pp.5954-5961.

[8] Arbab, E.A., Taleatu, B. and Mola, G.T., 2014. Environmental stability of PTB7: PCBM bulk heterojunction solar cell. Journal of Modern Optics,61(21), pp.1749-1753.

[9] Tremolet de Villers, B.J., O'Hara, K.A., Ostrowski, D.P., Biddle, P.H., Shaheen, S.E., Chabinyc, M.L., Olson, D.C. and Kopidakis, N., 2016. Removal of Residual Diiodooctane Improves Photostability of High-Performance Organic Solar Cell Polymers. Chemistry of Materials, 28(3), pp.876-884.

[10] Razzell-Hollis, J., Wade, J., Tsoi, W.C., Soon, Y., Durrant, J. and Kim, J.S., 2014. Photochemical stability of high efficiency PTB7: PC 70 BM solar cell blends. Journal of Materials Chemistry A, 2(47), pp.20189-20195.

[11] Balderrama, V.S., Sanchez, J.G., Estrada, M., Ferre-Borrull, J., Pallares, J. and Marsal, L.F., 2015. Relation of polymer degradation in air with the charge carrier concentration in PTB1, PTB7, and PCBM layers used in high-efficiency solar cells. IEEE Journal of Photovoltaics, 5(4), pp.1093-1099.

[12] Kettle, J., Waters, H., Ding, Z., Horie, M. and Smith, G.C., 2015. Chemical changes in PCPDTBT: PCBM solar cells using XPS and TOF-SIMS and use of inverted device structure for improving lifetime performance. Solar Energy Materials and Solar Cells, 141, pp.139-147. 
[13] Hintz, H., Peisert, H., Egelhaaf, H.J. and Chasse, T., 2011. Reversible and irreversible lightinduced p-doping of P3HT by oxygen studied by photoelectron spectroscopy (XPS/UPS). The Journal of Physical Chemistry C, 115(27), pp.13373-13376.

[14] Seo, H.O., Jeong, M.G., Kim, K.D., Kim, D.H., Kim, Y.D. and Lim, D.C., 2014. Studies of degradation behaviors of poly (3-hexylthiophene) layers by X-ray photoelectron spectroscopy. Surface and Interface Analysis, 46(8), pp.544-549.

[15] Norrman, K., Madsen, M.V., Gevorgyan, S.A. and Krebs, F.C., 2010. Degradation patterns in water and oxygen of an inverted polymer solar cell.Journal of the American Chemical Society, 132(47), pp.16883-16892.

[16] Darlatt, E., Muhsin, B., Roesch, R., Lupulescu, C., Roth, F., Kolbe, M., Gottwald, A., Hoppe, H. and Richter, M., 2016. Irradiation-induced degradation of PTB7 investigated by valence band and S $2 p$ photoelectron spectroscopy. Nanotechnology, 27(32), p.324005.

[17] Peet, J., Kim, J.Y., Coates, N.E., Ma, W.L., Moses, D., Heeger, A.J. and Bazan, G.C., 2007. Efficiency enhancement in low-bandgap polymer solar cells by processing with alkane dithiols. Nature materials, 6(7), pp.497-500.

[18] Waters, H., Bristow, N., Chang, S.W., Su, C.J., Wu, W.R., Jeng, U.S., Horie, M. and Kettle, J., 2014. Effect of processing additive 1, 8-octanedithiol on the lifetime of PCPDTBT based Organic Photovoltaics. Organic Electronics, 15(10), pp.2433-2438.

[19] Beamson, G. and Briggs, D. 1992. High resolution XPS of organic polymers: The Scienta ESCA300 database, Wiley, Chichester.

[20] Tsoi, W.C., Spencer, S.J., Yang, L., Ballantyne, A.M., Nicholson, P.G., Turnbull, A., Shard, A.G., Murphy, C.E., Bradley, D.D., Nelson, J. and Kim, J.S., 2011. Effect of crystallization on the electronic energy levels and thin film morphology of P3HT: PCBM blends. Macromolecules, 44(8), pp.29442952.

[21] Kettle, J., Waters, H., Horie, M., \& Smith, G. C. (2016). Alternative selection of processing additives to enhance the lifetime of OPVs. Journal of Physics D: Applied Physics, 49(8), 085601. 


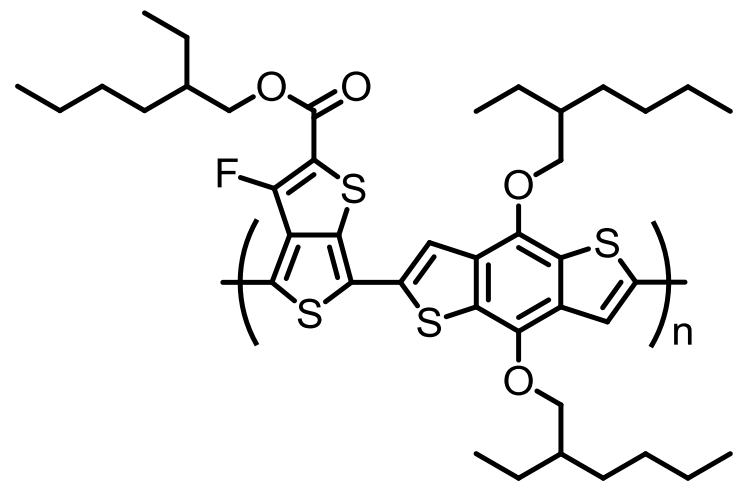

Figure 1: Chemical structure of PTB7 

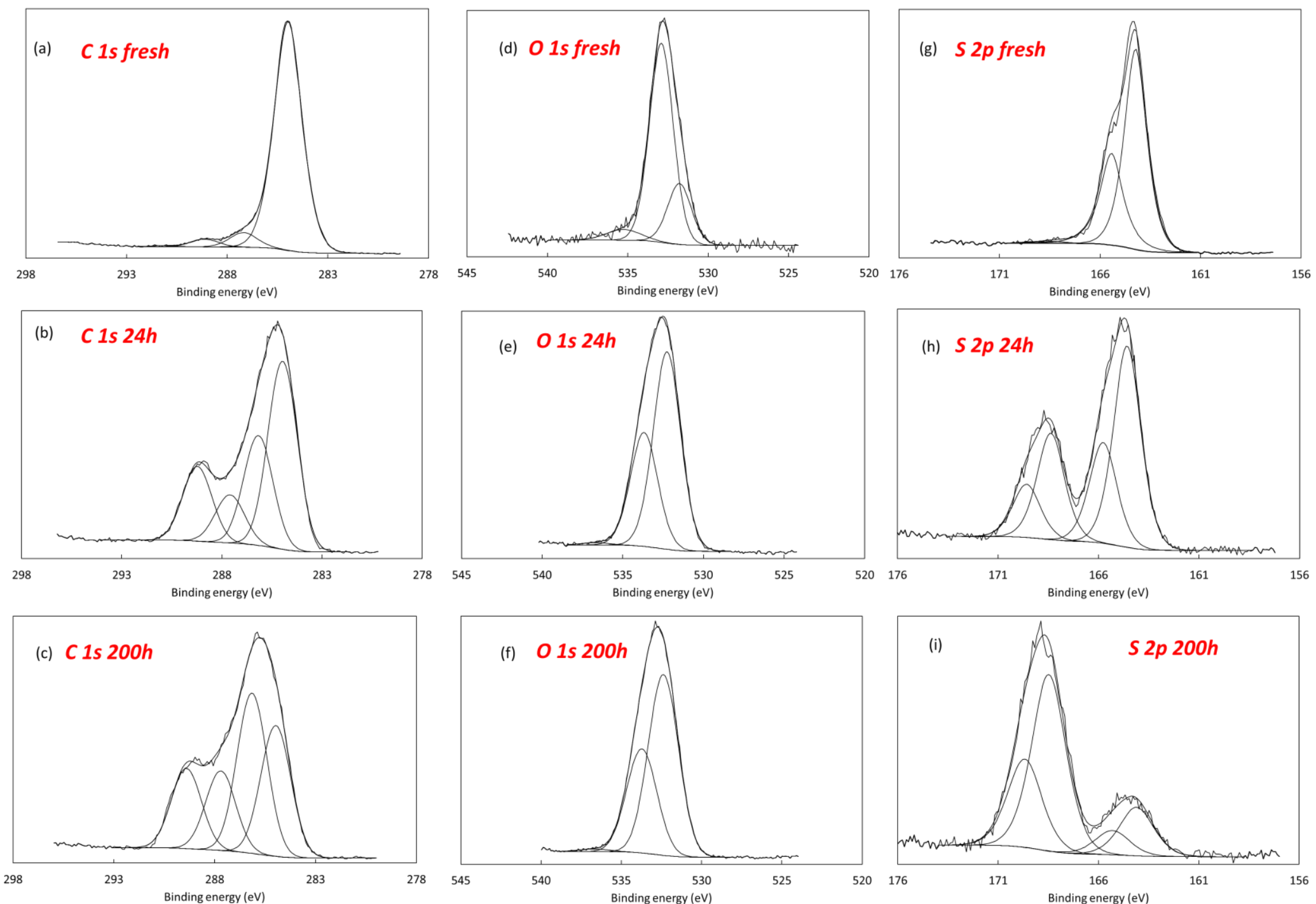

Figure 2: XPS spectra of PTB7 freshly prepared and aged for $24 \mathrm{~h}$ and 200 using ambient air light soaking facilities. Curve fitting is shown for (a) fresh C 1s, (b) C 1s aged 24 h, (c) C 1s aged $200 \mathrm{~h}$, (d) fresh O 1s, (e) O 1s aged $24 \mathrm{~h}$, (f) O 1s aged 200h, (g) fresh S 2p, (h) S $2 \mathrm{p}$ aged $24 \mathrm{~h}$, and (i) S $2 \mathrm{p}$ aged $200 \mathrm{~h}$. 

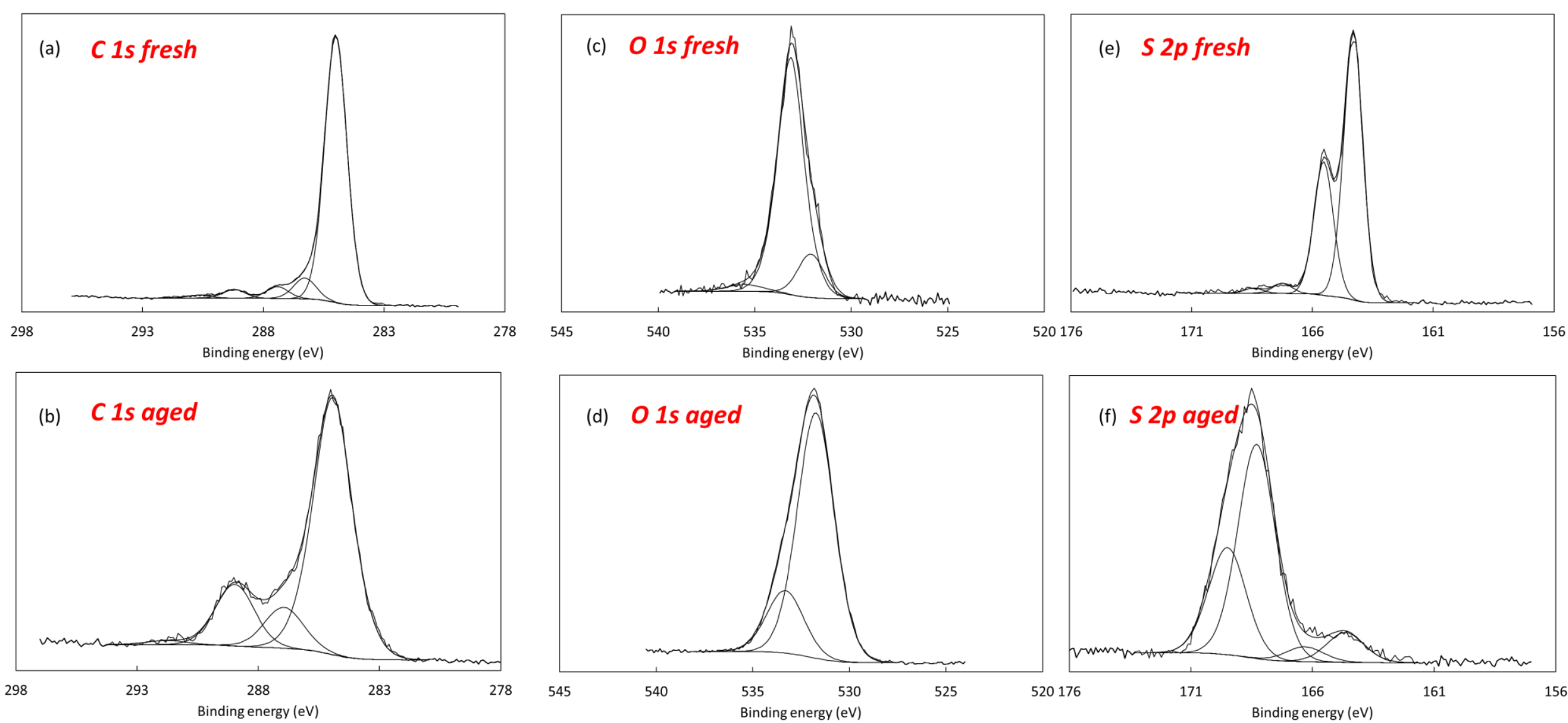

Figure 3: XPS spectra of PTB7:PC 71 BM with DIO process additive freshly prepared and aged for $200 \mathrm{~h}$ using ambient air light soaking facilities. Curve fitting is shown for (a) fresh and (b) aged C 1s, (c) fresh and (d) aged $O$ 1s spectra, (e) fresh and (f) aged $S 2 p$ spectra. 


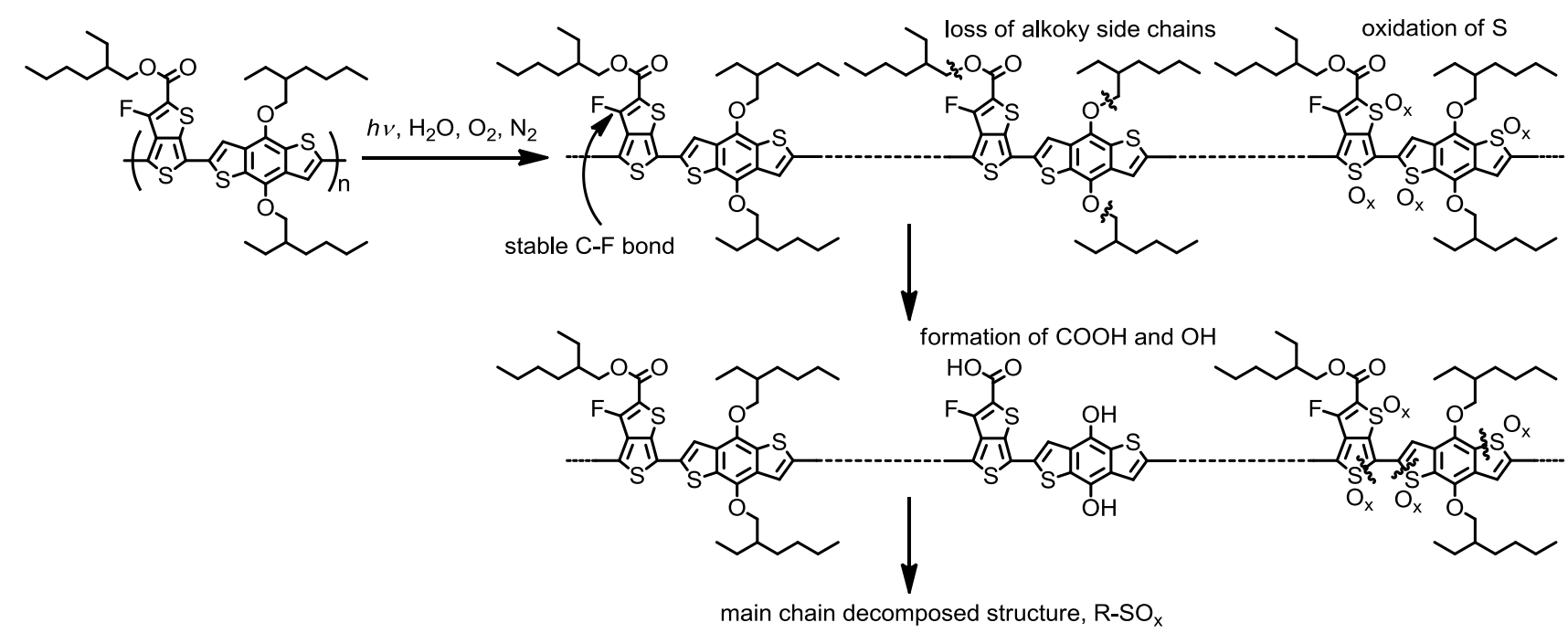

Figure 4: Deduced changes in chemical structure of PTB7 after light soaking in normal atmospheric conditions.

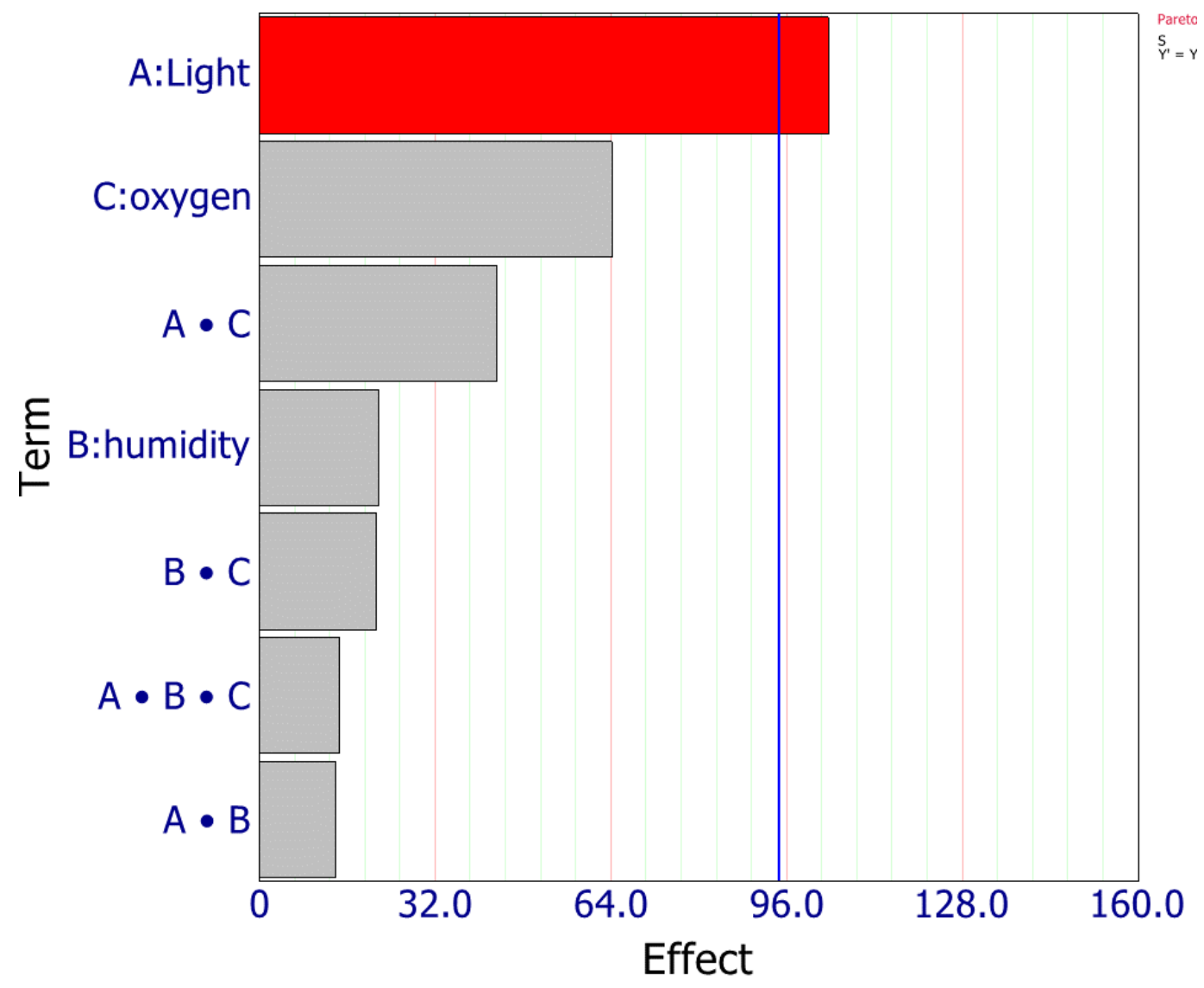

Figure 5: Pareto regression chart indicating the significant effects and interactions that cause oxidation of Sulphur in PTB7, calculated using a two level full factorial design of experiments. The blue line indicates the critical value and light is shown to be a significant term. For this analysis, two levels of stress were applied (i.e. light - 1 sun $\& 0$ sun, relative humidity- $5 \% \& 60 \%$, atmosphere $-\mathrm{N}_{2}$ and compressed air 


\begin{tabular}{|l|l|l|l|l|}
\hline \multirow{2}{*}{$\begin{array}{l}\text { element } \\
\text { \& line }\end{array}$} & \multicolumn{4}{|l|}{ Concentration (atom \%) } \\
\cline { 2 - 5 } & Expected & Fresh & $24 \mathrm{hr}$ & $200 \mathrm{hr}$ \\
\hline F 1s & 2 & 1.6 & 1.2 & 0.7 \\
O 1s & 8.0 & 7.4 & 29.4 & 34.8 \\
Sn 3d5/2 & - & 0.1 & 0.1 & 0.1 \\
C 1s & 82.0 & 81.7 & 59.4 & 55.1 \\
S 2p & 8.0 & 8.6 & 6.4 & 5.0 \\
Si 2p & - & 0.6 & 0.3 & 0.2 \\
Na 1s & - & & 0.3 & 1.2 \\
N 1s & - & & 2.8 & 3.0 \\
\hline
\end{tabular}

Table 1: Expected chemical stoichiometry of PTB7 and measured at 0, 24 and 200 hours

\begin{tabular}{|c|c|c|c|c|}
\hline Name & $\begin{array}{c}\text { PTB7: } \text { PC }_{71} \text { BM } \\
\text { fresh }\end{array}$ & $\begin{array}{c}\text { PTB7 PC71BM } \\
\text { 200h }\end{array}$ & $\begin{array}{c}\text { PTB7 PC71BM } \\
\text { with DIO fresh }\end{array}$ & $\begin{array}{c}\text { PTB7 PC71BM } \\
\text { with DIO 200h }\end{array}$ \\
\hline F 1s & 1.0 & 0.3 & 1.3 & 0.1 \\
O 1s & 6.3 & 32.3 & 6.5 & 32.5 \\
C 1s & 86.6 & 53.7 & 84.7 & 53.6 \\
S 2p & 6.0 & 5.3 & 7.3 & 5.7 \\
Si 2p & 0.2 & 2.2 & 0.0 & 2.5 \\
Na 1s & 0 & 0.6 & 0 & 0.6 \\
N 1s & 0 & 5.7 & 0.2 & 5.49 \\
C:S & 14.4 & 10.0 & 11.7 & 9.3 \\
\hline
\end{tabular}

Table 2: Chemical stoichiometry of PTB7:PC ${ }_{71} \mathrm{BM}$ and measured at 0 and 200 hours

\begin{tabular}{|c|c|c|c|c|c|c|c|c|c|c|c|}
\hline Atmosphere & $\mathrm{RH}$ & $\begin{array}{c}\text { Time } \\
\text { (hours) }\end{array}$ & $\begin{array}{l}\text { light } \\
/ \\
\text { dark }\end{array}$ & $\mathrm{F} 1 \mathrm{~s}$ & 0 1s & C 1s & $S 2 p$ & $\begin{array}{c}\% \mathrm{~S} \text { in } \\
\text { oxidised } \\
\text { state }\end{array}$ & $\begin{array}{l}\text { Change } \\
\text { in } \\
\text { oxidised } \\
\mathrm{S}\end{array}$ & $\begin{array}{c}\% \mathrm{C} \text { in } \\
\text { oxidised } \\
\text { state }\end{array}$ & $\begin{array}{c}\text { Change } \\
\text { in } \\
\text { oxidised } \\
\text { C }\end{array}$ \\
\hline \multicolumn{4}{|c|}{ Expected } & 2 & 8.0 & 82.0 & 8.0 & & & & \\
\hline \multicolumn{4}{|c|}{ Fresh } & 1.6 & 6.3 & 83.3 & 8.8 & 0.92 & $\mathrm{n} / \mathrm{a}$ & 9.1 & $\mathrm{n} / \mathrm{a}$ \\
\hline N2 & $<5$ & 3 & dark & 1.7 & 5.7 & 83.8 & 8.8 & 2.0 & $+117 \%$ & 10.5 & $+15 \%$ \\
\hline $\mathrm{N} 2$ & 60 & 3 & dark & 1.7 & 5.8 & 83.9 & 8.6 & 1.9 & $+107 \%$ & 4.0 & $-56 \%$ \\
\hline $\mathrm{N} 2$ & $<5$ & 3 & light & 1.6 & 6.0 & 83.5 & 8.9 & 2.4 & $+158 \%$ & 8.4 & $-7 \%$ \\
\hline $\mathrm{N} 2$ & 60 & 3 & light & 1.6 & 4.8 & 84.6 & 8.9 & 2.4 & $+158 \%$ & 8.3 & $-8 \%$ \\
\hline air & $<5$ & 3 & light & 1.7 & 6.8 & 82.9 & 8.6 & 3.4 & $+272 \%$ & 10.2 & $+8 \%$ \\
\hline air & 60 & 1 & light & 1.8 & 6.1 & 83.2 & 8.9 & 2.3 & $+148 \%$ & 9.8 & $+13 \%$ \\
\hline air & 60 & 3 & light & 1.59 & 7.57 & 82.11 & 8.85 & 4.5 & $+386 \%$ & 11.8 & $+30 \%$ \\
\hline
\end{tabular}

Table 3: Chemical stoichiometry of PTB7:PC ${ }_{71} B M$ degraded under different environmental states included variations in the level of humidity, oxygen and light illumination. 